\title{
Three Roles What Computer Act In Teaching And Learning
}

\author{
Li Yumei
}

\author{
Guangxi Economical Management College for Cadres Nanning, Guangxi, China 530007
}

\begin{abstract}
In this paper, we introduce the computer, a multifaceted tool that can be benefit to teachers and students in many different ways. The computer can be used in education in three basic ways: as a teacher, as a learner, and as an assistant. While the computer can do a lot, it isn't right for everything. In teaching and learning, as in model building, it is important to know when and how to use available tools appropriately.
\end{abstract}

Index Terms: Role; Computer; Teaching and learning

(C) 2012 Published by MECS Publisher. Selection and/or peer review under responsibility of the International Conference on E-Business System and Education Technology

\section{Introduction}

The computer is a multitool for teaching learning. It is s machine that can help with many different teaching and learning tasks. Rather than having separate tools for common tasks such as writing, drawing, filling, and developing multimedia, in the computer you have one tool that can do them all. Just by changing the software, like changing the attachment on a multitool, the computer can do many different thing.[1]

In popular terms, the word computer refers to a machine that processes information according to a set of instructions, A personal computer, also known as a PC or microcomputer, is intended for use by an individual, and since PCs proliferated in the 1970s and 1980s, they have become the focus of most of the computing industry. We emphasize the personal computer because it is such as a useful tool for teaching and learning. When most people picture a computer, they envision elements such as a keyboard, a box with a disk drive, and a display screen. This is actually a computer system, a collection of components that includes the computer and all of the devices used with the computer to realize or extend its capabilities. The hardware components of the computer system perform the basic functions that make everything work. Software is also an essential component of any computer system. Software, within the limitations set by the capabilities of the hardware, determines what the computer can do. When your computer operates, it carries out a complex set of actions that involves interplay among the various components of the system and you. Suppose that you wish to use your word processing software to compose a lesson plan. What role that computer will act in teaching and learning?

* Corresponding author.

E-mail address: 874674457 @qq.com 


\section{The roles what computer act in teaching and learning}

The computer is a powerful machine with a number if different uses in education. This diversity is reflected in a popular categorization scheme developed by Robert Taylor(1980). Taylor's "tutor, tool, tutee model" divides the educational applications of computers into three broad categories: computer as a teacher, computer as learner, and computer as assistant. [2]

The oldest use of the computer in education, dating back to the early 1960s, is as a tool that presents instruction directly to students. In this mode, the computer engages in activities traditionally associated wit human teachers or tutors. It presents instruction, use various media(text, graphics, audio, video), provides instructional activities or situations quizzes or otherwise requires interaction from learners, evaluates learners responses, provides feedback, and the determines appropriate follow-up activities. As teaching machines, computers can be highly interactive, individualized and infinitely patient. Applications that utilize the computer for teaching are usually labeled computer-assisted instruction(CAI), or computer-based instruction(CBI), computer-assisted learning(CAL), There are a number of common categories of computer-based instruction: drill, and practice, tutorial, simulation, instruction game, and problem solving. The chief advantage of the computer is its interactivity. Whereas a printed worksheet may leave space for a student's answer or an instructional video may pose a question for the viewer, there is no guarantee that the student will in fact respond. The computer can require a response; it can demand the learner's active involvement. When use as a teaching machine, the computer can be highly interactive, individualized, engaging, and infinitely patient. Research analyses of studies comparing computer-assisted instruction with traditional methods suggest that it produces slightly superior achievement, often in less time, and may produce improved attitudes toward computers and sometimes toward the subject matter itself(Kulik \& Kulik, 1991; Niemiec \& Wallberg, 1987). The positives effects are somewhat greater in the lower grades. More recent analyses(Kulik,2003) suggest that the results of integrating instructional technology in instruction are mixed, but do indicate that integration of instructional technology during the past decade has been more successful than earlier attempts. CAI has a long history of use, and it remains a popular option in classroom today, especially at the elementary level. CAI is usually used in a supporting or adjunct role. For example, we often use educational software during the instruction, but educational software are not all, they are only one part of a broader strategy of classroom activities. CAI can help students and free time for the teacher.

When the computer functions as the learner, or in what Taylor(1980) called "tutee" mode, the traditional roles of computer and learner are reversed. The computer becomes the learner; the student becomes the teacher. The goal is for the student to "teach" the computer to perform some task or to teach others some content through computer-based materials. [3]To achieve this goal, the student must learn how to perform the task and then must direct the computer to perform the task or present the content to others. This requires logical thinking and problem-solving skills, and as a result, many experts believe that this is one of the most valuable ways to use a computer in education. Activities of this sort may involve traditional computer languages such as Logo, BASIC, and C; when using a programming language, students must program the computer to perform a task(e.g., sum a set of numbers, draw a geometric figure on the computer's display screen). Students may also use multimedia/hypermedia authoring tools such as Hyperstudio, eZedia, and Director, or web page authoring tools such as Microsoft FrontPage and Macromedia Dreamweaver in this mode. When using authoring tools, the goal is for the student to create interactive presentations of content(e.g., tutorials, hypermedia programs) that others can use to learn about the content themselves. Thus, the student teaches others by developing computer-based materials.

As an assistant, the computer aids the teacher or learner in performing routine work tasks. It can function as a typewriter, a filing system, a financial worksheet, an artist's canvas, a drafting table, and much more. Software programs(commonly called applications) for these uses include word processors, graphics packages, presentation software, databases, spreadsheets, and telecommunications programs. Teachers often employ computers as labor-saving devices to produce instructional materials(e.g., printed matter, graphics, presentations)and manage their instruction (e.g., to maintain records and calculate student grades). Of course, 
learners can also employ the computer as an assistant. Students can use the computer to produce the materials (e.g., term papers, presentations) and can use software tools in ways that help them learn(e.g., for research and calculations).[4] What follows are descriptions of some of the most common computer applications for assisting teachers and learners as well as examples of how teachers and students can use them. First, word processors are the most widely used computer personal productivity tools. A word processor is a computer application that allows you to enter, edit, revise, format, store, retrieve and print text. Popular word processors for personal computers include Microsoft Word and Corel WordPerfect as well as those in integrated packages such as AppleWorks. There are also particularly easy-to-use word processors designed specifically for school use, such as Bank Street Writer. Second, while word processors are primarily tools for manipulating text, graphics tools handle pictorial information. Any computerized pictorial representation of information----drawing, chart, graph, animated figure, or photographic reproduction----- is called graphic. Popular graphics packages include Adobe Photoshop and Illustrator, Corel PhotoPaint and Draw, Macromedia Freehand and Fireworks, and Microsoft paint. Third, presentation software is designed for producing and displaying computer text and images, usually for presentation to a group. It replaces the function typically associated with traditional media presentation tools such as slides and overhead transparencies. Like other computer-based tools, it offers advantages over its traditional counterparts. Information is easily entered, edited, and presented. With the presentation package, it is easy to produce very professional looking presentations complete with multimedia elements, Popular presentation packages include Microsoft PowerPoint, Adobe Persuasion, Lotus Freelance Graphics, and Corel WordPerfect Presentations. Fourth, a database is nothing more than a collection of information. We are familiar with many examples of databases that are not computerized: a telephone book, a recipe file, a collection of old magazines. Computer databases offer significant advantages compared to their non-computer counterparts: they can hold huge amounts of information by category, and it is relatively easy to set up and manipulate computer databases. Most computer databases are structured in similar fashion. In other cases the database is a collection of data files that are interrelated in some way. For example, you might cross-reference your name-and-address file with your recipe file to make sure that you prepare a different dish the next time you have certain friends over for dinner. Popular computer spreadsheets, such as Microsoft Excel, include basic flat filer functionality. Programs such as Microsoft Access, FileMaker Pro, and Paradox fall into the relational database category. Fifth, electronic spreadsheets are general-purpose calculating tools derived from the paper worksheets once used by accountants. A spreadsheet is like a large piece of paper that has been marked off into rows and columns to form a grid. Most spreadsheets programs contain a wide variety of built-in mathematical functions(e.g., basic statistics, trigonometric functions, common financial functions) to facilitate calculations. Popular spreadsheets include Microsoft Excel, Lotus 1-2-3, and Quattro Pro. In addition, spreadsheets are found in integrated packages such as Microsoft Works and AppleWorks. The Cruncher is a spreadsheet program designed especially for school use. Sixth, telecommunications tools permit computer to communicate with other computers to share information. Today, we live in an era of global computer interconnectivity that brings a whole world of information to the personal computer user through computer networking and telecommunication. By accessing the Internet, you can instantly locate up-to-date information, communicate with others, and otherwise explore the far corners of cyberspace. While HTML can be created using any text editor, software packages that support the development of the web pages without the need to write HTML code include Microsoft FrontPage, Macromedia Dreamweaver, and Netscape Composer. The computer tools listed above are among the most popular and widely used. However, this list just begins to scratch the surface of what is available to teachers and learners for doing work of all kinds. For example, when one needs a finer degree of control over text and graphic layout than is available in typical word processors, teachers and students can turn to desktop publishing programs. Examples include Microsoft Publisher, Adobe PageMaker and Indesign, and Quark XPress.[5]

\section{Conclusion}

A computer can be used in education in three basic ways: as a teacher, as a learner, and as an assistant. 
Especially in the role of assistant, commonly used computer tools include word processor, graphic tools, presentation packages, databases, spreadsheets, and computer telecommunications tools among others. We described common features of each type of software and presented typical application for teachers and learners. Keep in mind that the computer with appropriate software is just a tool, albeit a very versatile one. While the computer can do a lot, it isn't right for everything. In teaching and learning, as in model building, it is important to know when and how to use available tools appropriately.

\section{References}

[1]. Paul Saettler, The Evolution of American Educational Technology. Libraries Unlimited, Inc. 1990

[2]. M.D.Roblyer. Integrating Educational technology into Teaching.Merrill Prentice Hall.2004

[3].James Lockard, Peter D.Abrams. Computers for Twenty-First Century Educators(sixth edition). AllynBacon, PearsonEducation, Inc.2004

[4]. Sharon E. Smaldino, James D.Russell, Robert Heinich, Michael Molenda. Instruction Technology And Media For Learning(Eighth Edition). Higher Education Press. 2005.8

[5]. Timothy J. Newby, Donald A. Stepich, James D.Lehman, James D.Russell. Educational Technology for Teaching and Learning.(Third Edition). Pearson Education ,Inc.2006 